\title{
«Le dandy» de Charles Baudelaire en «Nós, os inadaptados» de Vicente Risco
}

\author{
LAURA PiñeIro Pais \\ $\mathrm{UCM}$ \\ 1pineiro@ucm.es \\ Recibido: marzo de 2014. Aceptado: abril de 2014
}

\begin{abstract}
Resumo: A pegada da nómina de Charles Baudelaire foi incuestionable na literatura española en xeral, mais tamén na galega en particular, tanto nos autores máis andados da Xeración Nós, como nos máis novos, que nacen coas vangardas e se espallan ata a posmodernidade. Porén, o noso obxectivo con este artigo é comprobar de que forma influíu o texto baudelairiano na creación da ideoloxía e no proxecto ensaístico de Vicente Risco centrándonos fundamentalmente nos textos «Le dandy», que pertence a Le peintre de la vie moderne (1863), e «Nós, os inadaptados» (1933), un dos ensaios máis recoñecidos da nómina risquiana.
\end{abstract}

Palabras chave: Charles Baudelaire, Xeración Nós, ideoloxía, proxecto ensaístico, «Le dandy», «Nós, os inadaptados».

\begin{abstract}
The traces of Charles Baudelaire's work in Spanish literature in general, but also in Galician literature in particular, was unquestionable, not only on the eldest writers of the Nós Generation, but also on the youngest ones who were born during the avant-gardes period and lasted till postmodernism. Therefore, the aim of this article is to verify how Baudelaire had influence on the creation of the ideology and on Vicente Risco's essay project, by focusing on the texts «Le dandy», which belongs to Le peintre de la vie moderne (1863), and «Nós, os inadaptados» (1933), one of the most famous essays by Vicente Risco.
\end{abstract}

Keywords: Charles Baudelaire, Nós Generation, ideology, essay project, «Le dandy», «Nós, os inadaptados».

\section{INTRODUCIÓN}

Durante o transcurso do século XIX, Francia e a súa capital, París, adquiren unha vital importancia non só no panorama socio-político, senón tamén no artístico. O Romanticismo como corrente literaria supón a reacción definitiva contra o racionalismo que imperaba na Ilustración. Ben é certo que durante esa 
sucesión temporal o Romanticismo non se manifestou sempre de maneira homoxénea, senón que dos seus fundamentos xurdiron outros movementos, como por exemplo o parnasianismo ${ }^{1}$. Nun primeiro momento incluíuse a Baudelaire no movemento parnasiano, do que el mesmo se afasta por non concibir a idea de expulsar a moral da expresión artística. O decadentismo ou simbolis$\mathrm{mo}^{2}$, onde se inclúe a Baudelaire, Rimbaud e Mallarmé como máximos expoñentes, parte da liña temática do naturalismo e toma como núcleo de referencia o símbolo, o elemento artístico por antonomasia.

A situación socio-política de Galicia en torno ao 1900 era de cambios a grande escala: aparición de redes de teléfono, instalación de redes de iluminación eléctrica, chegada do ferrocarril ${ }^{3}$, construción de estradas, etc. Comezan a agromar os primeiros sindicatos e as primeiras orientacións políticas: socialista e nacionalista, dentro dun contexto gobernamental bipartito entre conservadores e liberais.

Os traballadores comezan a organizarse, ora en sindicatos de clase, ora en sociedades de orientación católica [...] As tendencias políticas monárquicas conviven cos movementos agraristas e novas formacións de orientación socialista e nacionalista. (Caseiro Nogueiras 2008:6)

Por toda esa serie de modificacións era necesaria a creación dun sistema ideolóxico que se adaptase ao novo século que nacía.

Vicente Risco, home culturalmente interesado desde a súa máis tenra xuventude, fundaméntase nas figuras das letras francesas ${ }^{4}$, entre moitas outras, para a conformación dun sistema ideolóxico-literario moderno. Por estas razóns tomamos como obxecto de estudo os ensaios «Le dandy», pertencente á obra Le peintre de la vie moderne (1863), e «Nós, os inadaptados», publicado no número 115 da revista Nós en 1933. Ao longo do noso estudo centrarémonos maioritariamente na figura do «dandy» e intentaremos esclarecer que repercusión tivo no imaxinario dos dous autores.

1 «Parnasianismo o parnasismo: Término con el que se alude a un grupo de poetas franceses que en 1866 publican conjuntamente sus composiciones poéticas en la revista Le Parnasse contemporain, de donde procede la denominación de dicho grupo [...] Esta nueva estética surge inicialmente como una reacción contra el Romanticismo en dos aspectos: crítica del principio de libertad absoluta en la creación artística [...] y abandono de la concepción utilitaria del arte al servicio de ideales políticos, sociales, etc.» (Estébanez Calderón 1999:807).

2 «Decadentismo: Término utilizado por algunos poetas y críticos franceses [...] que se consagra con el título de la revista Le décadent (1886), para significar un movimiento literario que se desarrolla a finales del siglo XIX. Entre los escritores más representativos de esta corriente destacan [...] Baudelaire [...], S. Mallarmé, Verlaine y J. K Huysmans [...]» (Ibídem, 263).

3 A chegada do ferrocarril a Galicia tivo lugar xa no ano 1873. O primeiro percorrido foi de Santiago a Carril (Vilagarcía de Arousa). A Ourense tardaría case unha década despois (1881). É significativo respecto a este acontecemento o poema de Curros Enríquez (1851-1908) «Chegada a Ourense da primeira locomotora» (1881).

${ }_{4}$ «As nosas leituras predominantes eran francesas: en poesía Baudelaire, Verlaine, Mallarmé, Rimbaud, Laforgue; en novela e conto Huysmanns, Peladan, Jean Lorrain, Rachilde; na críteca, Remy de Gourmont; no teatro Maeterlinck» («Nós, os inadaptados», p.116). 


\section{VICENTE RISCO}

Vicente Risco (1884-1963) nace nese contexto ourensán de rebumbio político e social e é precisamente esa realidade a que influirá de modo determinante na súa actividade literaria. Tras as primeiras colaboracións de xuventude en diferentes organismos como $O$ Miño $^{5}$ e La Centuria ${ }^{6}$, Risco comeza a publicar as súas primeiras obras xunto ao resto de figuras que compoñían a «Xeración Nós» (1900-1936). O ingreso nas «Irmandades da Fala» en 1917 supuxo un cambio substancial na ideoloxía risquiana, xa que foi precisamente nese grupo onde xurdiron as primeiras reflexións sobre esa doutrina política que os acompañaría por sempre: o nacionalismo. Como explica Olivia Rodríguez González (2001:81): «As súas preocupacións nacionalistas achábanse ligadas a un nacionalismo progresista, como seguidor da doutrina social do papa León XIII». A partir do ano 1917, Vicente Risco xa deixa entrever a súa ideoloxía nacionalista en diferentes ámbitos, xa fose en mitins ou nas páxinas do xornal A Nosa $T_{e r r a}{ }^{7}$. Polo tanto, a publicación da súa primeira obra ensaística non tardaría en chegar e en 1920 publicou Teoría do nacionalismo galego. Neste ensaio o autor recolle todo o pensamento galeguista anterior, centrado, fundamentalmente, nunha das grandes figuras do momento: Manuel Murguía ${ }^{8}$. Esta obra é considerada como iniciática, xa que nela Risco plasma a ideoloxía que o acompañará ata o estoupido da Guerra Civil Española: rexeitamento do mundo moderno9, inadaptación que provoca a evasión do mundo, rexeitamento do racionalismo en todas as súas formas ${ }^{10}$, substitución das nacións de oriente polas de occidente ${ }^{11}$

5 En 1910, o mozo Risco colabora neste xornal elaborando algún dos artigos máis feroces de crítica contra a sociedade burguesa do seu tempo. Por temor a represalias, en moitos casos opta por asinar eses artigos con pseudónimos como Rajú Sahib (onde deixa entrever a súa fascinación pola cultura oriental) e Polichinela. Moi en menor medida publica co seu nome.

6 Revista neosófica creada en 1917. Os colaboradores desenvolveron a súa actividade en lingua castelá. O traballo máis destacado de La Centuria foi, sen dúbida, o labor de tradución das grandes figuras da literatura europea.

7 Vicente Risco expón a súa teoría nacionalista por vez primeira en 1918, nun artigo que escribe para o xornal A Nosa Terra. Pouco despois, esas ideas serán compendiadas na obra Teoría do Nacionalismo Galego.

8 «Di o ilustre Murguía que Galicia foi estado soberano os cento setenta anos que durou a monarquía dos Suevos; no tempo da Reconquista e mais dende o século XIII ó XVI, para ser Estado independente non lle cumpría senón ter rei propio, gozou tódalas ventaxas do réxime autónomo hastra o século XIX» (Vicente Risco 1994, IV:22).

9 «Estase vendo a crise do europeísmo. É o sol posto dunha civilización» (Vicente Risco 1994, IV:43).

10 O único movemento que o autor concibe é o Romanticismo, porque asenta as súas bases no predominio dos sentimentos sobre a razón.

11 «Mais o que é agora, todo parece sinalar un desprazamento dese centro da civilización, dende o Mediterráneo cara ó Atlántico. [...] A civilización atlántica ha ser, polo tanto, outra cousa do que a civilización mediterránea. [...] É outra cousa a que hai que agardar dos pobos atlánticos: non é unha superación do presente, senón a creación do futuro» (Ibídem, 44). 
e o cambio da orientación budista polo catolicismo ${ }^{12}$. Neste ensaio, Risco expón tamén que é para el o Nacionalismo galego, que parte do Volksgeist ${ }^{13}$ alemán:

Emprégase a verba nacionalismo para designa-lo corpo de doutrinas que informan todo o movemento de reivindicación da personalidade dos grupos naturais por frente da sorbencia dos Estados históricos. [...] Nacionalismo galego, quere dicir polo tanto, a doutrina que informa o movemento de reivindicación da personalidade de Galicia frente da sorbencia do centralismo español. (Vicente Risco 1994, IV:9)

Segundo esta liña temática, o autor realiza un percorrido polo nacionalismo a nivel mundial e clarifica algúns dos conceptos relacionados con esta idea como son o rexionalismo, o feudalismo e, por suposto, «o absurdo centralista». Ademais fai fincapé na ética, na nacionalidade, na teleoloxía e na pragmática nacionalistas. Risco incorpora todas estas ideas á realidade galega, porque é consciente da necesidade de adaptar a ideoloxía aos novos tempos.

En 1933, Vicente Risco publica «Nós, os inadaptados», un breve ensaio onde recolle o pensamento anterior á súa etapa galeguista. As ideas que están presentes neste texto son comúns ás que aparecían xa na súa novela $O$ porco de pé (1928): crítica expresa do marxismo, sátira das clases cultas, enfrontamento entre materia e espírito encarnado nos seus personaxes principais, reivindicación do orientalismo como forma de civilización superior, desprezo pola sociedade urbana, medo á revolución, desconfianza fronte á política e os seus dirixentes, etc.

Tras a fundación do Partido Galeguista, Risco toma unha posición política distinta á anterior e o sentimento patriótico tornouse en hostilidade no que respecta a Galicia e ao seu idioma. O catolicismo do que comezaba a facer gala nos anos vinte é elevado ao seu máximo expoñente e decide abandonar o Partido Galeguista para ingresar na Dereita Galeguista, un partido que se caracterizaba precisamente por iso, pola defensa radical da Igrexa Católica ${ }^{14}$. En 1930 viaxa a Berlín a realizar cursos de etnografía ${ }^{15}$, tarefa que xa viña desempeñan-

12 «Educado nun ambiente católico de provincias, o raro de Ourense especialízase en saberes ocultos e chega a se interesar pola espiritualidade oriental, que a través da vía bíblico-xudía o conduce de novo a unha práctica tradicional católica. O regreso terá lugar na segunda fase da súa militancia nacionalista [...] entre os anos 1925 e 1931» (Rodríguez González 2001: 139).

13 «É. J. G. Herder, dentro da corrente alemana, quen sistematiza este tipo de ideoloxía nacionalista que conta co concepto de Volksgeist como elemento constitutivo da nacionalidade» (Ibídem, 91).

14 A viaxe que o autor realizará a Alemaña en 1930 «será determinante na súa evolución ideolóxica cara a posturas cada vez máis conservadoras sintetizables nun catolicismo integrista, no dereitismo político e no reaccionarismo social, o que irá minguando o seu protagonismo político no seo do nacionalismo e o conducirá á ruptura co Partido Galeguista trala súa integración na Fronte Popular, o que o animaría a intentar crear unha Dereita Galeguista a comezos de 1936, proxecto axiña abortado polas circunstancias» (Dolores Vilavedra 1999:176).

15 «Da crenza do determinismo xeográfico, alicerce dun nacionalismo esencialista e bioloxicista, arrinca o seu interese pola etnografía e antropoloxía galegas concretado en obras como $D a$ 
do desde había tempo na revista $N^{\prime} s^{16}$ e noutros organismos como o «Seminario de Estudos Galegos». A Alemaña que se abre ante os seus ollos consegue marabillalo ${ }^{17}$, porque lle presenta o tipo de sociedade que el ambicionaba: sociedade decadente ${ }^{18}$, materialista, destruída polo marxismo, o freudismo e o capitalis$\mathrm{mo}^{19}$. Desta fascinación xermánica nacen as series de artigos «Da Alemaña»e «Mitteleuropa» (1934), que describen esa viaxe física e ideolóxica pola Europa Central. Como explica Rodríguez González (2001:159): «O eixo temático desta longa serie de artigos [...] xira en torno á defensa dun catolicismo tradicional e o ataque [...] ó comunismo e á propagación das ideas marxistas nos costumes morais».

Nestes traballos podemos apreciar, ademais dos elementos que lle presentaba Alemaña, a reincidencia do autor noutras cuestións xa coñecidas como a exaltación da relixión como oposición entre o clasicismo e o Romanticismo que, segundo afirma Rodríguez González (2001:161), «é un dos poucos momentos optimistas reflectidos no diario [...], impregnado de agresividade. Contrasta coa continua sensación de desalento». O catolicismo sería, segundo Risco, o único recurso que lle quedaría a esa Europa en decadencia. A causa deste cambio vertixinoso na ideoloxía do autor nacen todas as teorías que o sitúan a favor dos fascismos de comezos de século ${ }^{20}$, nas que se basean os seus detractores para condenalo culturalmente ${ }^{21}$.

Finalmente, por mor do abandono do galeguismo en 1936, a actividade literaria de Vicente Risco en lingua galega reduciuse considerablemente, polo que o único que se conserva desta etapa é o material compendiado na obra Historia de Galiza, publicada en Bos Aires en 1962.

mitoloxía popular: os mouros encantados (1927), Ensaio dun programa pró estudio da literatura popular galega (1928), así como o seu labor no SEG» (Ibidem, 177).

16 «Na revista Nós existía un apartado que levaba por nome «Arquivo filolóxico e etnográfico de Galiza», no que publicaban Risco e o seu equipo de colaboradores os seus achados en materia etnográfica» (Rodríguez González 2001:88).

17 «Non me pasou isto coa impresión xeral da cidade, que cada día se me foi afincando máis na alma. Algún tempo despois, aínda dicía eu en Berlín que Bonn era a cidade máis fermosa que vira na miña vida [...] e laiábame de non quedar en Bonn» (Vicente Risco 1994, I:299).

$18 \ll$ J. G. Beramendi propón ó respecto a tese de que por fin Vicente Risco aclara a súa teoría da decadencia occidental, posto que remata por atopar aquí e agora unha causa moi concreta, cunha única solución posible» (Rodríguez González 2001:159).

19 «O romantismo, en efecto, choutaba por riba de moitos valados, e nisto do amor, puña a paixón por riba da moral tradicional e dos costumes admitidos. Mais a diferencia é ben grande. En primeiro termo, aquilo era a paixón [...] e agora non é iso: agora máis ben trátase de suprimir todo o estado paixonal, que se considera morboso, produto da contención sexual. Agora reina a friaxe; trátase do sexo exclusivamente: materialismo, ou sexa marxismo» (Vicente Risco 1994, I:344).

20 «A actitude de Risco tras 1936 é susceptible de diversas interpretacións. En todo caso, é innegable o seu apoio público ó réxime franquista con artigos en La Región e Misión (na que publicaría unha serie de ensaios de refutación do marxismo, de defensa dogmática dun catolicismo integrista e de louvanza a Franco) [...]» (Dolores Vilavedra 1999:178).

${ }_{21}$ «Vicente Risco é visto hoxe como unha das figuras fundamentais do galeguismo cultural e político, cando se pode dicir que pretendeu secuestralo intelectualmente» (Suso de Toro El país, 28/1/2011) 


\section{2. «LE DANDY» DE CHARLES BAUDELAIRE}

Como xa adiantabamos ao comezo deste estudo, a influencia que tivo Charles Baudelaire na literatura española ${ }^{22}$ foi incuestionable, mais tamén na literatura galega, onde atopamos vestixios da obra baudelairiana tanto nos textos dos clásicos como Vicente Risco (1884-1963) ou Manoel Antonio (1900-1930), como nos máis novos como Lois Pereiro (1958-1996).

Le peintre de la vie moderne (1863) é unha obra que compendia algunhas reflexións do autor sobre arte e modernidade. Estes ensaios non só tiveron gran relevancia no seu tempo, senón que as súas ideas foron de transcendencia fundamental ao longo do século XX:

[El autor] imprime un giro radical a la visión artística tradicional occidental, decisivo para el desarrollo creativo posterior - no solo en las vanguardias de principios del siglo XX, donde se percibe quizás con mayor claridad, sino de terrenos profundamente insospechados como el arte de género actual $[\ldots]$ y también para la madurez del pensamiento filosófico contemporáneo al anticiparse en años a la crítica posmoderna. (Godoy Domínguez 2008:3)

Esta obra aséntase en base ao concepto de modernidade que o autor relaciona co seu tempo actual. Esa «vie moderne» caracterízase pola busca do común, do concreto a través do abstracto. O moderno será, en certo modo, un tempo novo que se caracterizará pola transitoriedade e a fugacidade. Baudelaire extrapola o concepto de modernidade a todas as artes, entre as que se inclúe tamén a pintura. A arte é un elemento que está en pleno proceso de cambio, ao igual que o están tamén a política, a economía e a ciencia dentro da historia. Os elementos fixos da modernidade son, neste caso, a burguesía como clase en auxe e a revolución que se estaba fraguando ${ }^{23}$. Esta modernidade está inserida nun contexto urbano, na cidade de París. A cidade que xorde é a contemporánea, ataviada de elementos modernos que a diferencian da realidade natural. Baudelaire déixase dominar pola nostalxia do perdido, ou sexa, daquela natureza de outro$\mathrm{ra}$, a que nunca fora profanada pola man do home. $\mathrm{O}$ autor non rexeita o progreso propiamente dito, senón que ten un conflito interno entre ese progreso e o papel que xoga nel o ser humano inmerso na realidade urbana ${ }^{24}$. A arte para Baudelaire, en tanto que está incluído nun contexto urbano, natural e cíclico, non pode ter a súa medida no natural.

22 Influencia de Baudelaire nos modernistas españois Juan Ramón Jiménez e nos irmáns Antonio e Manuel Machado. Continuarán o percorrido simbolista outros autores como Pedro Salinas, Luís Cernuda, Federico García Lorca, Ramón Gómez de la Serna o Jaime Gil de Biedma. (Extraído de Medina Arjona 2009).

23 Revolución Industrial.

24 «Lo que engendra el spleen está escrito en el primer verso del libro: el pecado, el error, la idiotez, la avaricia [...] Es el mundo moderno, los valores modernos, en una palabra, la desilusión del hombre de una generación cuyos padres hicieron la Revolución para algo más que para matar al rey y proclamar la república y que contempla, consternada, a qué infierno se ha llegado» (Alain Verjat 1994:975). 
Durante os trece capítulos que compoñen a obra Le peintre de la vie moder$n e$, o autor realiza unha pescuda da beleza na fealdade e considera «o feo» como obxecto artístico. A musa canónica desaparece na modernidade ${ }^{25}$ e o autor recorre a unha musa enferma ou morta para representar a súa concepción ideal de beleza. Baudelaire atopa a fermosura no cotián, no degradado, deixando a un lado o concepto prototípico do sublime ${ }^{26}$.

«Le dandy» correspóndese co noveno capítulo da obra. Nel, o autor distingue os dous tipos de homes que imperaban na sociedade decimonónica: os «hommes vulgaires» e os «dandies». Ao longo de todo o ensaio, que el mesmo cualifica de aparente digresión ${ }^{27}$, preséntasenos a antítese entre os dous tipos de homes nunha sociedade non igualitaria. O dandi está representado como un home rico e ocioso, educado no luxo e na elegancia. O dandismo atópase á marxe das leis, aínda que está suxeito a unhas «lois rigoureuses auxquelles sont strictement soumis tous ses sujets, quelles que soient d'ailleurs la fougue et l'indépendance de leur caractère» (Baudelaire 130). O dandi leva implícitas unha serie de particularidades precisamente para ser diferenciado do home vulgar. $\mathrm{O}$ dandi está eximido de calquera profesión. A única tarefa que ten que desempeñar é a do cultivo de «l'idée du beau dans leur personne, de satisfaire leurs passions, de sentir et de penser» (ídem). O dandi está dotado dunha gran fortuna, o que lle permite optar a esa vida ociosa e vestir de maneira tan elegante. Baudelaire considera esa indumentaria como o «symbole de la supériorité aristocratique de son esprit» (132). Por outra banda, o home vulgar ten que traballar para satisfacer a «grossière passion» (ídem) de obter riquezas. O diñeiro, ao igual que o amor, é unha «répugnante utilité» (130) propia deses homes comúns. O dandi, a diferenza do home vulgar, non aspira ao amor como algo esencial porque non lle dá importancia ao culto das paixóns, nin tampouco se conmove ante elas.

Unha das ideas fundamentais que documentamos neste texto é a da sinxeleza como distinción absoluta, que era o que os dandis ambicionaban por enriba de calquera cousa. A sinxeleza estaba relacionada coa liberdade creadora. $\mathrm{O}$ feito de facerse orixinal era primordial, era a necesidade de diferenciarse dos homes comúns. A caída na trivialidade era a maior preocupación do dandi, mentres que a busca da felicidade non era o seu obxectivo, senón que se trataba dun anhelo característico da muller ou do home vulgar ${ }^{28}$.

25 «Quand elle eut de mes os sucé toute la moelle, / Et que languissamment je me tournai vers elle / Pour lui rendre un baiser d'amour, je ne vis plus / Qu'une outre aux flancs gluants, toute pleine de pus!» (Baudelaire 1972:187).

26 «En su mundo, la belleza es de piedra, la belleza alcanzable, propia de las mujeres, será siempre degradada, testimonio, en el presente, de la imposibilidad de preservar la pureza del pasado» (Alain Verjat 1995:975).

27 «Ce qui a pu paraître au lecteur une digression n'en est pas une, en vérité. Les considérations et les rêveries morales qui surgissent des dessins d'un artiste sont, dans beaucoup de cas, la meilleure traduction que le critique en puisse faire» (Charles Baudelaire 2008:136).

28 «C'est avant tout le besoin ardent de se faire une originalité, contenu dans les limites extérieures des convenances. C'est une espèce de culte de soi-même, qui peut survivre à la recherche du bonheur à trouver dans autrui, dans la femme, par exemple; qui peut survivre même à tout ce qu'on appelle les illusions» (Ibídem 132). 
O dandi está circundado polo espiritualismo e o estoicismo ${ }^{29}$, a diferenza do que acontece co home vulgar e estes son, segundo explica Baudelaire, «une gymnastique propre à fortifier la volonté et à discipliner l'âme» (134). A doutrina estoica permitíalle ao dandi o dominio de si mesmo e a capacidade para vencer calquera situación adversa. $\mathrm{O}$ dandi aprende a obedecer para dominarse e para se volver un ser impasible.

O dandismo aparece nas épocas ancoradas na decadencia, onde «le dandysme apparaît surtout aux époques transitoires où la démocratie n'est pas encore toute-puissante, où l'aristocratie n'est que partiellement chancelante et avilie» (ídem). O dandi soña coa creación dun novo proxecto aristocrático baseado nas «facultés les plus précieuses, les plus indestructibles, et sur les dons célestes que le travail et l'argent ne peuvent conférer» (ídem). Baudelaire considera o dandismo como o solpor dunha civilización e destaca a melancolía e a inadaptación deses homes encarnados na figura do dandi.

Ademais desta distinción dos homes, Baudelaire realiza unha crítica contra a literatura francesa. $\mathrm{O}$ autor xulga a carencia de dandis na creación literaria do seu país e compáraa coa realidade da literatura inglesa: «Les dandies se font chez nous de plus en plus rares, tandis que chez nos voisins, en Angleterre [...] laisseront longtemps encore une place aux héritiers de Sheridan, de Brummel et de Byron» (136).

\section{O DANDISMO EN «NÓS, OS INADAPTADOS» DE VICENTE RISCO}

Pola súa banda, Vicente Risco publica o ensaio «Nós, os inadaptados» no número 115 da revista Nós. Como xa anticiparamos, o autor expón neste texto o seu pensamento e o de todos os da súa xeración respecto da política e da creación literarias. Para iso presenta a distinción psicolóxica entre as novas xeracións, os mozos, e os homes do seu tempo, os vellos. Ao igual que expuxo Baudelaire no seu tempo, Risco rexeita o igualitarismo social entre os homes, co que non sería posible este tipo de sociedade dandista.

Risco amosa a súa incerteza sobre o galeguismo no futuro e distingue a inversión do pensamento galego culturalmente militante; é dicir, que xa non percibe a ousadía nos mozos para combater a política a través da cultura:

Algús mozos [...] continuadores máis ou menos trocados dos qu'hai uns anos chamábanse a sí mesmos os novos, preténdese unha sorte de reviramento total do pensamento galego culturalmente militante. Justifícase ainda mais cando, ollando dend'a a nosa banda, o pensamento galego atópase n-un intre no que non podemos adiantar con seguranza vendo o d'hoxe, o que vai a ser mañá. (Vicente Risco 1979:115)

29 O estoicismo é unha escola ética que se pregunta sobre a felicidade. O estoicismo oponse ao materialismo que impera na esencia do home vulgar. O home estoico caracterízase pola súa insurrección e tamén pola desconfianza que lle crean todos e cada un dos praceres existentes. 
Porén, Risco observa tamén a existencia de certas semellanzas entre os homes do seu tempo e as novas xeracións, xa que ambos son os últimos superviventes dun gran ciclo histórico: o Rexurdimento ${ }^{30}$. O Rexurdimento é o «soleil couchant; comme l'astre qui décline» ao que aludía Baudelaire (2008:136), a representación dese orgullo humano nesa época que xa queda atrás. Risco elucubra sobre a idea da decadencia, propugnada por Oswald Spengler ${ }^{31}$ e por el mesmo ${ }^{32}$.

En «Nós, os inadaptados» o autor reflexiona acerca da problemática dese home inadaptado e cualifícao como «un dos grandes probremas das decadenzas» (Risco 1979:115). O inadaptado é ese ser rebelde, insatisfeito, inconformista, pero á vez, vencido da vida. Esta idea está documentada tamén no texto de Baudelaire, no que o dandi non ten máis saída que a que lle proporciona o espiritualismo e o estoicismo. O inadaptado non é partidario da realidade histórica na que vive, ao igual que o dandi, que non está rexido por ningunha lei que non lle vaia preestablecida na súa esencia. Cita como arquetipo fundamental de inadaptación a Des Esseintes, o heroe da novela À rebours de Joris Karl Huysmanns ${ }^{33}$ :

O tipo deuse adoito na fin do século derradeiro, e atopou cecais a mais nidia espresión literaria no Des Esseintes de Huysmanns. O tídoo da novela de Huysmanns dío todo: À rebours; porqu'iso é o que son os inadaptados, os que van a contrafío do seu tempo, os que non acaen cos seus contemporáneos. (Vicente Risco 1979:116)

Por outra banda, Risco realiza nestas páxinas un percorrido polas principais fontes literarias que tomou o seu grupo para a creación dun imaxinario común. Entre elas destacaban as figuras francesas da segunda metade do século XIX:

O noso esprito zugou d'esas fontes unha ideología vaga, non ben determiñada, cecais contraditoria, qu'entrou en nós fondamente e para sempre, e pouco e pouco, paseniñamente foi collendo corpo e determiñou o qu' habiamos ser, pensar e sintir. (Ídem)

Ese pensamento, segundo o expón o autor, pertence a unha xeración «qu' ainda acordou os derradeiros esprendores d'un mundo que morre» (ídem), é dicir, aos últimos superviventes da etapa de esplendor que supuxo o Rexurdi-

30 Período de renacemento da literatura galega que comeza con Frei Martín Sarmiento e culmina na publicación de Cantares gallegos de Rosalía de Castro. O Rexurdimento non só supuxo a modernización da cultura galega, senón tamén da historia e da política do momento.

31 Oswald Spengler (1880-1936) foi un filósofo e historiador alemán que destacou pola obra en dous volumes, A decadencia de Occidente (Der Untergang des Abendlandes). Foi o antecedente de Las tinieblas de Occidente, asinada por Vicente Risco.

32 «A ideia da decadenza d'Oucidente era unha ideia vivente en nós moito antes de que Spengler tivera pensado en escribir o seu libro. Pol-o 1912, tiña eu escrito outro libro no mesmo senso que ficóu inédito, e qu'o de Spengler inutilizóu pra sempre» (Risco 1979:115).

33 Cfr. Nota 2 (Páx.2). 
mento en Galicia. Tras compendiar todas as figuras fundamentais das que beberon Risco e a súa xeración, o autor formula unha definición de inadaptado:

Os inadaptados son, por definición, os insatisfeitos do mundo sensíbele, os nemigos da realidade cotián, os que procuran fuxir do meio qu'os arrodeia. D’eiqui a conceición da arte com' evasión [...] Nós non desbotámolo meio natural, non condanabámol-a natureza [...] sintíamos já d'aquela a intimidade da peisaje, e atopabámoslle millor paladar canto mais salvaje, canto menos aparecera profanada pol-a mau do home. (Ídem)

Se analizamos esta explicación sobre o inadaptado, documentamos varias semellanzas entre este modelo e a proposta baudelairiana: insatisfacción do home co mundo que o arrodea, o gusto pola natureza salvaxe, a concepción da arte como evasión, etc. $\mathrm{O}$ inadaptado foxe do medio social no que está inserido, non do ambiente que lle proporciona a natureza.

Se recordamos a crítica que o autor facía a esa carencia de rebeldía por parte dos mozos, nesta segunda parte do ensaio, Risco afirma que existe nalgúns deses homes certos ápices de insurrección pero que se trata dunha sublevación diferente porque «ises rapaces móvense por un intrés social, levan, trabucada ou non, unha ideia de melloramento, de pretensa perfeizón, de reforma da sociedade» (1979:117). Por outra banda, observamos a rebeldía do inadaptado, que consistía na indiferenza polos factores sociais e os seus roles. Esta idea xa está documentada con anterioridade en Baudelaire, porque o seu dandi pretendía fundar unha aristocracia nova que non estivese baseada no don social do traballo e do diñeiro. A diferenza do dandi, o inadaptado víase na obriga de traballar para poder comer, aínda que esa ocupación non debía de ser tomada en serio porque para el «compañeirismo, solidaridade profesional ou de clás, eran com'a politeca, os intereses púbricos, a reforma social, a sociedade futura, a revolución, a utopía, preocupaciós e angueiras propias dos filisteus» (ídem). A partir deste momento, o autor preséntanos o antagonista do inadaptado, o filisteu: $« \mathrm{O}$ filisteu era por definición o home preocupado da cousa púbrica e dos seus graves asuntos: da política, do sufragio universal, dos programas dos partidos, das formas de goberno [...], do Capital, do Traballo» (ídem).

Ao igual que acontecía no caso do dandi, Risco amósanos o reflexo dunha sociedade dual na que distinguimos dous tipos de canons humanos, o do inadaptado e o do filisteo. En O porco de pé (1928) Risco encarna estes dous prototipos nos personaxes principais da obra: Don Celidonio e o Doutor Alveiros. O primeiro representa o cacique, un home unicamente preocupado polo ascenso na escala social a través dos beneficios que lle proporciona a política, mentres que o Doutor Alveiros caracterízase pola súa virtude e polo cultivo do espírito. O inadaptado destacaba por ser antigregario e antisocial, en contraposición co filisteo, que era un ser concibido para as relacións en sociedade ${ }^{34}$.

34 «A diéxese estructúrase arredor dun sistema de oposicións binarias que enfrontan a materia co espírito, representadas por Don Celidonio e o Doutor Alveiros respectivamente, ata que ambos, víctimas do filisteísmo imperante, rematan por converxer: a derrota de Alveiros é a victoria da vulgaridade sobre os valores das elites [...]» (Dolores Vilavedra 1999:179). 
O individualismo é outra característica común entre o dandi e o inadaptado. Risco toma o culto moral do eu promovido por Maurice Barrés ${ }^{35}$ e trasládao á caracterización dese home de espírito: «Todo nos estaba permitido non sendo a infidelidade do propio eu, todo esente unha treición a propia persoalidade, todo quitando un devecemento do individo» (118). O dandi non forma parte de ningunha clase, senón que constitúe unha casta en si mesmo. De aí provén o retrato que Baudelaire fai do dandi, ao que describe como «derniers représentants de l'orgueil humain et verse des flots d'oubli sur les traces de ces prodigieux mirmidons» (Baudelaire 2008:136). Esa necesidade ardente de orixinalidade e a pretensión de escapar das convencións son tomadas por Risco para a construción dese modelo individualista e consciente de que na vida moderna a liberdade é imposible. Para o autor "«ser diferente é ser esistente», cada un de nos puña o seu empeño en non asemellarse aos outros en opiniós, en gustos, en costumes [...]» (Risco 1979:118). Risco entende que esa moral individualista non pode ser pensada para todos os homes, senón que está considerada como un privilexio: «Era unha verdadeira moral de caste, mais non de caste social, senón de caste espirtual» (Ibidem 119). Para o inadaptado, o tempo pasado é centrífugo mentres que o presente é centrípeto e gregario, polo que permanece ancorado na nostalxia da realidade anterior. Desta idea agroma unha implacable crítica social ao órgano de poder que imperaba nas realidades dos dous autores: por unha banda, a democracia burguesa da Francia do século XIX ${ }^{36}$ e por outro o Ourense caciquil de comezos do século XX.

No ecuador do ensaio de Vicente Risco faise referencia expresa ao termo dandismo. $\mathrm{O}$ inadaptado vese obrigado a buscar no exótico unha solución á realidade inmediata, que destacaba pola súa vulgaridade e fealdade: «Sabiamos, ademais, qu'esta vulgaridade, qu'esta fealdade non tiñan enmenda, e por iso eramos pesimistas [...] O mundo, para nós, era cousa qu'había qu'aturar c'unha postura de dandysmo» (ídem).

Tanto en Baudelaire como en Risco non se advirte ese concepto xerárquico do home, senón que a importancia reside na superioridade do espírito, non tanto na árbore xenealóxica. A única tarefa do dandi era «cultiver l'idée du beau dans leur personne, de satisfaire leurs passions, de sentir et de penser» (Baudelaire 2008:130), moi similar á do inadaptado, que para entender a arte éralle unicamente necesario «poseer un ingrediente psíquico que por non ter unha verba mellor chamabamos nós esprito» (Vicente Risco 1979:120). O esprito non era o xenio, nin tampouco o talento, aínda que o xenio é difícil que se manifeste en homes sen esprito. Co talento pódese ser todo, mais nunca se conseguirá ser artista. $\mathrm{O}$ autor aquí realiza unha diferenza moi clara entre a arte e $\mathrm{o}$ talento e considera que o esprito non é un concepto estético, aínda que podería

35 Maurice Barrès (1862-1923) foi un político e pensador francés, que destacou polas súas teorías do eu. Foi un dos reformuladores da teoría nacionalista en clave conservadora. «Barrès creyó ver en España a una nación resistente al proceso de racionalización económica y burocrática que, a su juicio, amenazaba a Francia» (González Cuevas 2007:202).

36 «No tiene mucha mejor opinión de la sociedad burguesa a la que le reprocha su mojigatería y su hipocresía, su egoísmo, su cinismo, en una palabra su falsedad engreída» (Alain Verjat 1994:975). 
selo se se tratase de algo excepcional. Como exemplo de home carente de esprito cita Risco a Thomas Edison ${ }^{37}$. Segundo Risco, a arte está restrinxida porque non implica un rol social, senón que «era o goce esotérico dos escolleitos, era unha revelación místeca» (ídem).

Finalmente, a proposta de Risco tórnase tripartita, xa que distingue tres tipos de homes seguindo a clasificación proposta polos gnósticos ${ }^{38}$ e os priscilianistas ${ }^{39}$ : homes hylicos, homes psíquicos e homes pneumáticos. Os hylicos son os homes vulgares, os psíquicos os homes de talento e os pneumáticos os homes de esprito. A converxencia entre hylicos e pneumáticos asentaría a base das sociedades burguesas modernas e, como consecuencia, os psíquicos veríanse expulsados do contexto social ${ }^{40}$.

Vicente Risco continúa o seu ensaio expoñendo qué supuxo para a súa xeración a fin de século desde o punto de vista do humanismo e de que forma xurdiu o nacionalismo galego. A resposta nacionalista vén dada pola novela Arredor de si (1930) de Ramón Otero Pedrayo. O seu protagonista, Adrián Solovio, non reflicte a biografía dun único home, senón a de todos os da súa xeración ${ }^{41}$. Atopan en Galicia a identidade buscada polo mundo. Para a creación do mundo interior de Adrián Solovio, Otero Pedrayo toma como modelo o xa proposto por Huysmanns, aínda que tamén se advirte unha certa similitude de natureza biográfica entre o personaxe e o autor ${ }^{42}$. Como conclusións, Risco propón o paso dunha actitude contemplativa cara unha activa e expón os dous únicos camiños

37 Thomas Alva Edison (1847-1931) foi un dos máis prolíficos inventores da era contemporánea. Entre a súa nómina inventiva atopamos a lámpada, descuberta no ano 1879, o fonógrafo e a abundante contribución ao mundo do cine: «Pero como en tantas otras cosas, fueron los trabajos de Thomas Alva Edison, en 1889, los que llevaron al invento de lo que él llamó kinetógrafo: primera cámara sonora [...]» (Celdrán Gomariz 2009:232).

38 «Gnosticismo: Doutrina filosófica e relixiosa que profesaban algunhas comunidades dos primeiros séculos do cristianismo, que crían na salvación do home pola vía do coñecemento» (Extraído do DRAG: 21/03/2014).

39 «Priscilianismo: Movemento relixioso do séc. IV inspirado na doutrina de Prisciliano, considerado herético pola Igrexa, que se baseaba nunha doutrina de carácter ascético inspirada na tradición gnóstica e oposta á opulencia das xerarquías eclesiásticas» (Extraído do DRAG: 21/03/2014).

40 «Toda gran cultura xurde d'un estado anterior en qu'os homes vulgares, os hylicos, predomiñan e fan a historia. E xurde a gran cultura pol-o aparecimento [...] d'un fato d'almas egregias, supernormás, d'homes con esprito, qu'abesullan o senso e crían a protoforma d'aquela cultura [...] Paseniñamente vai medrando a preponderancia social do filisteu, namentral-a críteca, rillando os fundamentos de todo, minando o basamento espirtual da cultura e traguendo o primado da utilidade, a preocupación económica, preocupación filistea por autonomasia, materializando a vida, vai faguendo qu'esta vaia voltando a cair nas maus dos vulgares [...] os bárbaros armados das armas da cultura aos que pertence o trunfo final» (Risco 1979:121).

${ }^{41}$ «Arredor de si, unha novela [...] que se adoita interpretar como unha biografía ficcional da peripecia vital dos homes de Nós» (Dolores Vilavedra 1999:191).

42 «Este personaxe, inspirado na vida do propio Otero, acadóu o seu pleno desenvolvemento en Arredor de sí, pero a súa primeira formulación atopámola no protagonista de Escrito na néboa, que ademáis leva o mesmo nome, cunha lixeira variante gráfica» (Carlos Casares 1981:94). 
que lle quedan ao home de esprito: por unha banda o da introversión, o do cultivo do seu mundo interior e por outro o do nacionalismo, o intento de crear un mundo desde a súa perspectiva salvando os seus propios valores.

\section{CONCLUSIÓNS}

En conclusión, tras o percorrido realizado polos textos de Risco e Baudelaire observamos que o ourensán tomou «Le dandy» como modelo para explicar en que consistía a súa identidade e a dos da súa xeración, contrapoñéndoa ao resto dos homes, os vulgares. O inadaptado nace como un alter ego do dandi baudelairiano, pero é unha proposta que se implica máis cá anterior, xa que non se aferra ao estoicismo máis apático. O inadaptado é un vencido da vida, un home que analiza a súa función na sociedade desde a máis profunda aflición. É un modelo máis realista porque desde o comezo é consciente da súa derrota. As vías de escape que propón Risco son as da introversión e o nacionalismo, aínda que sabe que ambas supoñen máis unha ilusión ca unha posibilidade en si mesmas. Dota a ese anhelo dunha validez inconmensurable, porque a realidade supón un instante histórico, mentres que o soño, polo simple feito de ser soñado, xa se mantén imperecedoiro no mundo interior.

Tanto o inadaptado como o dandi están inseridos en dúas realidades paralelas: contexto social decadente que provoca inconformismo; non condenan o mundo natural senón que unicamente desprezan a sociedade urbana; desinterese polas leis e polos elementos sociais, o que lles crea esa necesidade de orixinalidade e de segregación que deriva no individualismo. Estes dous modelos non están concibidos para unha sociedade xerárquica na que prevalezan as relacións de parentesco. Tanto no dandi como no inadaptado prima o cultivo espiritual por riba do social.

No que respecta á crítica social que realizan ambos autores, a efectuada por Baudelaire é máis comedida porque está incluída nunha obra que ten como único destinatario a burguesía da súa época, que era a que podía facerse cos elementos artísticos. Relaciona estes dous arquetipos de homes con elementos tanto literarios como pictóricos, mentres que Risco expón sen reservas a situación do intelectual galego de comezos do século XX. Os contextos nos que se publican as dúas obras son completamente distintos, de aí provén a diferenza de matices entre a crítica realizada por Risco e a feita por Baudelaire.

$\mathrm{O}$ elemento temporal é a diferenza fundamental entre as dúas propostas. A pesar de que Risco toma a concepción moderna que propón Baudelaire para a creación do seu ensaio, o seu inadaptado supón o último paso da modernidade do século dezanove á posmodernidade, onde xa se advirte un cambio de mentalidade que non só influirá na ideoloxía do autor e da súa xeración, senón tamén en toda a literatura galega posterior. 


\section{BIBLIOGRAFÍA}

Angueira, A. (2013) Das copras de Sarmiento ós cantares de Rosalía de Castro, Berlín, Frank \& Timme.

Baudelaire, C. (1972), Les fleurs du mal, Claude Pichois (ed.), París, Gallimard.

Baudelaire, C. (2008), Le peintre de la vie moderne, Silvia Acierno y Julio Baquero Cruz (eds.), Madrid, Langre.

Casares, C. (1981), Otero Pedrayo, Vigo, Galaxia.

Caseiro Nogueira, D. (2008), «Unidade didáctica «O porco de pé»», Ourense, Fundación Vicente Risco.

Celdrán Gomariz, P. (2009) El gran libro de la historia de las cosas, Madrid, La esfera de los libros

Estébanez Calderón, D. (1999) Diccionario de términos literarios, Madrid, Alianza.

Fernández del Riego, F. (1975) Historia da literatura galega, Vigo, Galaxia.

Godoy Domínguez, M. J. (2008) «El pintor de la vida moderna, de Charles Baudelaire» [En liña], Fedro, Revista de estética y teoría de las artes, n. $^{\circ} 7$, pp. 3-25. En: http://institucional.us.es/fedro/uploads/pdf/n7/pasajes.pdf

González Cuevas, P. C. (2007) «Maurice Barrès y España» [En liña], Historia Contemporánea, n. ${ }^{\circ}$ 34, pp. 201-224. En http://www.historiacontemporanea. ehu.es/s0021con/eu/contenidos/boletin_revista/00021_revista_hc34/es_revista/adjuntos/34_09.pdf

López Corredoira, M. (2007) «Leer a Oswald Spengler en los tiempos de decadencia de Occidente» [En liña], El manifiesto, n. ${ }^{\circ}$ 9, pp. 63-80. En http:// www.iac.es/galeria/martinlc/spengler.pdf

Medina Arjona, E. (2009) «Lectura. Recepción de Baudelaire en España» [En liña], Rapsoda, Revista de literatura, n. ${ }^{\circ} 1$, pp. 128-134. En http://pendientedemigracion.ucm.es/info/rapsoda/num1/serta/medina.pdf

Risco, V. (1979) «Nós, os inadaptados». Nós: Boletín mensual da cultura galega, órgao da sociedade galega de pubricaciós, Tomo V (97-120), Vigo, Galaxia, pp. 115-123

Risco, V. (1994) Obras Completas. Vol 1, Vigo, Galaxia.

Risco, V. (1994) Obras Completas. Vol 4, Vigo, Galaxia.

Rodríguez González, O. (2001) Estética e teoría da cultura en Vicente Risco, Vigo: Galaxia.

Toro, S. de (2011) «Vicente Risco, tráxico bufón, intruso perturbador» [En liña] El País, 28-1-2011, en: http://elpais.com/diario/2011/01/28/galicia/1296213506_850215.html 
Verjat, A. (1994) «La lírica». Historia de la literatura francesa, Javier del Prado (coord.), Madrid, Cátedra, pp. 927-1001

Vilavedra, D. (1999) Historia da literatura galega, Vigo, Galaxia.

\section{Recursos electrónicos:}

Dicionario da Real Academia Galega (RAG). En liña: http://www.realacademiagalega.org/dicionario\#inicio.do 
